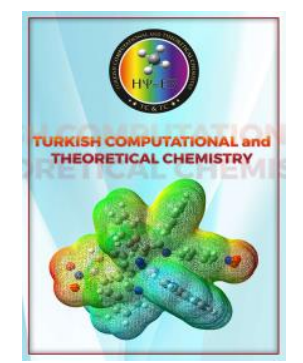

Received: 13.04.2021
Turkish Computational and Theoretical Chemistry

Turkish Comp Theo Chem (TC\&TC)

Volume(Issue): 5(1) - Year: 2021 - Pages: 39-50

e-ISSN: 2602-3237

https://doi.org/10.33435/tcandtc. 914768

Accepted: 04.05 .2021

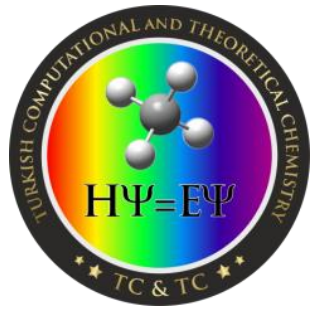

Research Article

\title{
The effects of protecting and acyl groups on the conformation of benzyl $\alpha-L-$ rhamnopyranosides: An in silico study
}

\author{
Farzana Islam ${ }^{\mathrm{a}}$, Md. Rezaur Rahman ${ }^{\mathrm{b}}$, Mohammed M. Matin ${ }^{1, \mathrm{a}}$
}

aBioorganic and Medicinal Chemistry Laboratory, Department of Chemistry, Faculty of Science, University of Chittagong, Chittagong, 4331, Bangladesh.

${ }^{b}$ Department of Chemical Engineering and Energy Sustainability, Faculty of Engineering, Universiti Malaysia Sarawak, Jalan Datuk Mohammad Musa, Kota Samarahan, 94300, Malaysia

\begin{abstract}
:
Carbohydrate fatty acid (CFA) esters especially rhamnopyranoside esters having both the hydrophilic and lipophilic nature showed broader applications including anticancer activities. It was reported that appropriate conformation is needed for better activities and conformational distortion reduced antimicrobial functionality. In this context, two different esters series of benzyl $\alpha$-L-rhamnopyranosides, one with 2,3-O-acetonide group and the other one without acetonide group, were subjected for the density functional theory (DFT) optimization. The optimized structures with 2,3-O-acetonide rhamnopyranoside clearly showed distortion from the regular ${ }^{1} C_{4}$ chair conformation while rhamnopyranoside esters without 2,3-O-acetonide functionality exhibited almost regular ${ }^{1} C_{4}$ chair conformation. Also, the number and position of acyl group(s) present in the benzyl rhamnopyranoside imposes a small effect on their pyranose chair conformation. Thermodynamic properties including frontier molecular orbitals (FMO) and molecular electrostatic potential (MEP) of both the series of rhamnopyranosides are also discussed which indicated that 4-O-acyl rhamnopyranosides are more reactive than the 3-O-acyl analogues.
\end{abstract}

Keywords: Conformational study; DFT optimization; MEP; Rhamnopyranoside; Sugar esters (SEs); Thermodynamic properties.

\section{Graphical Abstract}
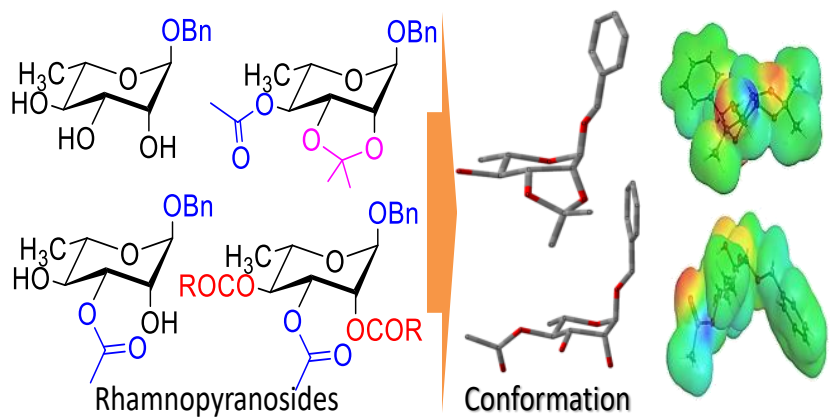

Highlights
-Acetonide protected
rhamnopyranosides are highly
distorted from ${ }^{1} C_{4}$ chair conformation.
-Acyl group at C-4 position of
rhamnopyranoside imposes more
electrophilicity than at C-3 position.
- The number and chain length of acyl
group(s) in rhamnopyranoside affect
very little on its chair conformation.

Highlights

rhamnopyranosides are highly distorted from ${ }^{1} C_{4}$ chair conformation. -Acyl group at $\mathrm{C}-4$ position of rhamnopyranoside imposes more electrophilicity than at $\mathrm{C}-3$ position. group(s) in rhamnopyranoside affect very little on its chair conformation.

\section{Introduction}

The most ubiquitous biomolecules named carbohydrates play the pivotal role in many biological processes. However, many natural carbohydrate compounds showed poor binding affinities [1] which led their structural modification to improves applicability in various fields including drug candidates [2-4]. Structural modification with

\footnotetext{
${ }^{1}$ Corresponding Authors

e-mail: mahbubchem@cu.ac.bd; mmmatin2004@yahoo.co.in
} 
one or more acyl group(s) led to the formation of sugar esters (SEs) [5-6] having diverse applications in different industries [7-10]. However, stereocontrolled i.e. site selective synthesis of SEs has long been recognized as a significant challenge in carbohydrate chemistry [11-12]. The presence of several secondary hydroxyl groups with almost similar reactivity imposes a barrier on selective esterification [13]. In this respect various methods were developed and employed successfully [1419].

Among the SEs, synthetic rhamnopyranosides were reported to show promising activities like neuroprotective [20], antidepressant [21-22], anticarcinogenic [23], antimicrobial [24-26], and pharmacological properties [27] as well as in bioremediation of pollutants. For example, rhamnopyranose 4-O-, 2,3-di- $O$ - and 2,3,4-tri- $O$ acyl esters isolated from roots of Scrophularia buergeriana were found to reduce glutamateinduced neurotoxicity [20]. Rhamnose esters bearing various plant extracts have long been used in Oriental medicine as a treatment for fever, constipation, swelling, neuritis and laryngitis [2829]. Recently, the synthesis and interfacial properties of rhamnopyranoside derived bolaamphiphile type biosurfactant materials (e.g. 1, Figure 1) are reported [30]. Although having effects for immunological activities there have no precise correlations been made between a particular constituent of these compounds and an observed pharmacological activity [31].

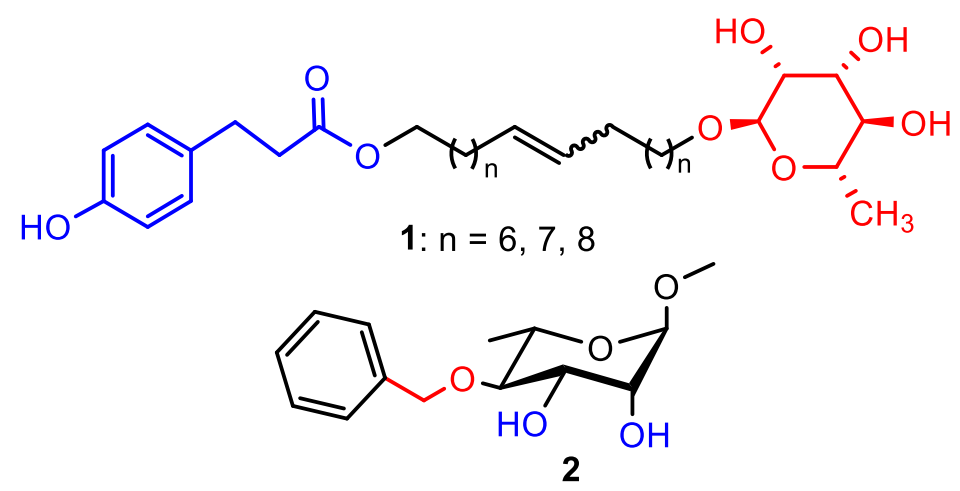

Figure 1. Structure of compound 1, and 2.

The shape or conformation of a molecule greatly influences its rates of reaction and other properties. The spatial shape of branched sugar molecules (oligosaccharides) depends mainly on the conformational features of the branch points. The conformational properties of such branched oligosaccharides may cause considerable anomalies in NMR spectra with chemical shift values [32]. The proximity of the conformational states of the disaccharide units in branched oligosaccharides has been described by analyzing both the nOe experimental data and theoretical conformational analysis [33]. Thus, many workers reported X-ray crystallographic data for appropriate assignment of conformation. For example, Pendril et al. established the structure of methyl 4-O-benzyl- $\alpha$-Lrhamnopyranoside (2) which structurally exists in ${ }^{1} C_{4}$ chair conformation with some H-bonding [34]. Now a days, density functional theory (DFT) approach with the B3LYP functional with both the $6-31 G(d, p)$ and $6-311+G(d, p)$ basis sets are used for the investigation of the structural (conformational) and energetic parameters which provide information on the potential biological activity [35]. Hence, the present work is designed to investigate the stable conformation(s) of acylated benzyl $\alpha$-L-rhamnopyranoside derivatives with the aid of quantum mechanical DFT approaches.

Our previous publications presented synthesis, characterization and biological activities of different protected and un-protected rhamnopyranoside esters [36-40]. Here, basically we report an investigation related to the effect of acetonide protecting group and acyl group(s) on the conformation of benzyl $\alpha$-L-rhamnopyranoside (3) on the basis of quantum mechanical DFT studies.

\section{Computational Method}

\subsection{Materials}

For the present study we have considered two series of esters of benzyl $\alpha$-L-rhamnopyranoside (3). The first series (4-6 and 7a,b) were prepared via 2,3-Oacetonide protection of compound $\mathbf{3}$ (Figure 2) [41]. The second series ( 8 and $\mathbf{9 a - d}$ ) were prepared using 
dibutyltin oxide method (Figure 2) [42]. All these benzyl rhamnopyranosides 4-9 were characterized by spectroscopic technique and elemental analyses, and their antimicrobial activities were also reported $[27,41]$.

\subsection{Methods}

Initially, the structure benzyl $\alpha$-Lrhamnopyranoside (3) with appropriate geometry was taken from available structure database namely ChemSpider. The rest of the rhamnopyranoside structures for 4-9 were drawn in the GaussView (5.0) program [43] keeping this standard stereochemistry of the molecules. These rhamnopyranoside molecules were optimized with Gaussian 09 program at DFT (B3LYP) computing method [44-45] with 6-31G basis set [46-47] of DFT at $298 \mathrm{~K}$ and $1 \mathrm{~atm}$ without any solvent.<smiles>CC1C(O)C(O)C(C)C(O)C(O)C1O</smiles><smiles>[R]C1C(C)C(OC(C)=O)C([R])C(C)C1OCc1ccccc1</smiles>

7a: $\mathrm{R}=\mathrm{COC}_{4} \mathrm{H}_{9}$ 7b: $\mathrm{R}=\mathrm{COC}_{5} \mathrm{H}_{11}$

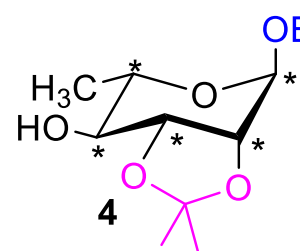<smiles>CC(=O)OC1C(C)OC2OC(C)(C)OC1C2OCc1ccccc1</smiles><smiles>CC(=O)O[C@H]1C(C)OC2OC(Cc3ccccc3)C(O)C1O2</smiles>

Figure 2. Structure of rhamnopyranosides 3-9 (* indicates stereocentre).

FMO (frontier molecular orbital) energy like HOMO (highest occupied molecular orbital), LUMO (lowest unoccupied molecular orbital) and HOMO-LUMO gap were calculated from the optimized structures using GaussView (5.0) program. DOS plots were obtained from GaussSum 3.0. Molecular electrostatic potential (MEP) was also calculated at the same level of DFT, and MEP visualization was conducted by online WebMO demo server [16, 39].

\section{Results and discussion}

\subsection{Conformations of rhamnopyranosides 3-9a-} d

The structural shape and conformation of biologically active compounds immensely influenced their interactions with receptor proteins [48]. In this respect many researchers conducted conformational study of methyl $\alpha$-Lrhamnopyranoside (10) [49], methyl 4- $O$-benzyl- $\alpha$ L-rhamnopyranoside (2) [34] and methyl 2,3,4-tri$O$-acetyl- $\alpha$-L-rhamnopyranoside (11) [50]. From their X-ray crystal structures of compounds 2, 1011 they found that these exist in regular ${ }^{1} C_{4}$ conformation (Figure 3). In the past few decades development of quantum mechanical and spectroscopic techniques made it easier to study the structure and conformation of bioactive molecules [51-52]. Thus, in the present study quantum mechanical DFT (B3LYP) optimization was used for the conformational study of several derivatives of benzyl rhamnopyranoside $\mathbf{3}$.<smiles>COC1OC(O)C(O)C(O)C1O</smiles>

10

regular

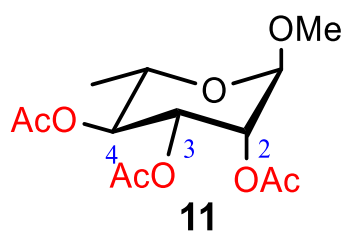
11

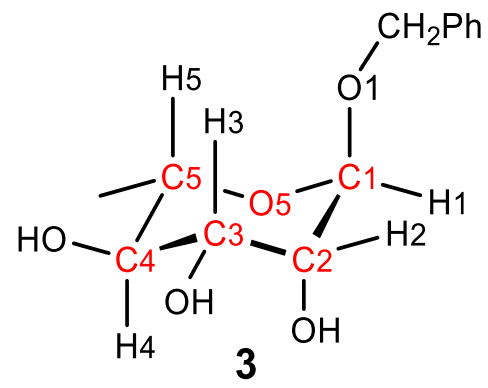

Figure 3. Regular chair conformation of $\mathbf{1 0}$ and $\mathbf{1 1}$. 
Farzana Islam, Md. Rezaur Rahman, Mohammed M. Matin

Initially, we considered first series of It is clear from Table 1 that incorporation of rhamnopyranosides 4-7a,b (Figure 2). In acetonide ring at C-2 and C-3 position as in $\mathbf{4}$ of compound $\mathbf{4}$ and $\mathbf{5}$, one five-membered rhamnopyranoside 3 increased bond angles at $\angle \mathrm{O} 5$ isopropylidene ring is fused with the six-membered $\quad \mathrm{C} 1-\mathrm{C} 2, \quad \angle \mathrm{C} 1-\mathrm{C} 2-\mathrm{C} 3 \quad$ and $\angle \mathrm{C} 2-\mathrm{C} 3-\mathrm{C} 4, \quad$ and pyranose ring at $\mathrm{C}-2$ and $\mathrm{C}-3$ position. Necessary bond angle and dihedral angle of the optimized decreased at $\angle \mathrm{C} 4-\mathrm{C} 5-\mathrm{O} 5$.

rhamnopyranoside 3-7a,b are presented in Table 1.

Table 1. Bond angle and dihedral angle of rhamnopyranoside 3-7a,b.

\begin{tabular}{|c|c|c|c|c|c|c|}
\hline \multirow{2}{*}{ Molecule } & \multicolumn{6}{|c|}{ Bond angle in degree } \\
\hline & $\mathrm{O} 5-\mathrm{C} 1-\mathrm{C} 2$ & $\mathrm{C} 1-\mathrm{C} 2-\mathrm{C} 3$ & $\mathrm{C} 2-\mathrm{C} 3-\mathrm{C} 4$ & C3-C4-C5 & $\mathrm{C} 4-\mathrm{C} 5-\mathrm{O} 5$ & $\mathrm{C} 5-\mathrm{O} 5-\mathrm{C} 1$ \\
\hline 3 & 113.7 & 111.3 & 110.8 & 110.4 & 107.3 & 115.3 \\
\hline 4 & 114.3 & 115.6 & 113.6 & 110.8 & 106.1 & 115.1 \\
\hline 5 & 114.0 & 116.0 & 112.0 & 111.4 & 105.7 & 114.8 \\
\hline 6 & 113.2 & 111.3 & 110.6 & 110.8 & 107.1 & 115.5 \\
\hline $7 \mathbf{a}$ & 112.0 & 110.7 & 110.9 & 111.1 & 109.0 & 115.3 \\
\hline \multirow[t]{3}{*}{$7 \mathbf{b}$} & 112.0 & 110.7 & 111.0 & 110.9 & 109.0 & 115.2 \\
\hline & \multicolumn{6}{|c|}{ Dihedral angle, in degree } \\
\hline & $\mathrm{H} 1-\mathrm{C} 1-\mathrm{C} 2-\mathrm{H} 2$ & \multicolumn{2}{|c|}{ H2-C2-C3-H3 } & $\mathrm{H} 3-\mathrm{C} 3-\mathrm{C} 4-\mathrm{H} 4$ & \multicolumn{2}{|c|}{$\mathrm{H} 4-\mathrm{C} 4-\mathrm{C} 5-\mathrm{H} 5$} \\
\hline 3 & 76.12 & \multicolumn{2}{|c|}{49.26} & -177.54 & \multicolumn{2}{|c|}{-177.44} \\
\hline 4 & 83.93 & \multicolumn{2}{|l|}{32.40} & -163.87 & \multicolumn{2}{|l|}{-174.68} \\
\hline 5 & 82.11 & \multicolumn{2}{|l|}{35.00} & -162.59 & \multicolumn{2}{|l|}{-176.92} \\
\hline 6 & 75.44 & \multicolumn{2}{|l|}{49.43} & -173.96 & \multicolumn{2}{|l|}{178.64} \\
\hline $7 \mathbf{a}$ & 68.10 & \multicolumn{2}{|l|}{53.99} & -170.24 & \multicolumn{2}{|l|}{173.40} \\
\hline $7 b$ & 68.27 & \multicolumn{2}{|l|}{53.88} & -170.20 & \multicolumn{2}{|l|}{176.65} \\
\hline
\end{tabular}

*All these values were calculated from DFT (B3LYP) method and 6-31G basis set.

Also, huge increase of dihedral angle at $\angle \mathrm{H} 1-\mathrm{C} 1-$ $\mathrm{C} 2-\mathrm{H} 2 \quad\left(\sim 8^{\circ}\right)$ and $\angle \mathrm{H} 3-\mathrm{C} 3-\mathrm{C} 4-\mathrm{H} 4 \quad\left(\sim 15^{\circ}\right)$, and decrease at $\angle \mathrm{H} 2-\mathrm{C} 2-\mathrm{C} 3-\mathrm{H} 3$ than the compound 3 created huge deviation in the pyranose ring conformation. This ultimately caused deviation of chair conformation and compound $\mathbf{4}$ exist as distorted ${ }^{1} C_{4}$ chair conformation as shown in Figure 4. Further incorporation of acetyl group at C-4 position of compound $\mathbf{4}$ formed the compound $\mathbf{5}$ which was found almost similar distorted ${ }^{1} C_{4}$ chair conformation. Removal of 2,3-O-acetonide group from 5 created compound $\mathbf{6}$ with the elimination of extra distortion and found to exist in regular ${ }^{1} C_{4}$ chair conformation (Table 1, Figure 4). Again, addition of further acyl groups at C-2 and C-3 positions of $\mathbf{6}$ formed $\mathbf{7 a}, \mathbf{b}$. The presence of extra acyl groups at these positions caused very small bond angle change and conformationaly found almost similar to the regular ${ }^{1} C_{4}$ chair conformation (Figure 4).

Interestingly, it was observed that in all the compounds 3-9a,b the glycosidic benzyl group at C-1 position located exo-orientation with respect to pyranose ring (Figure 4). The bond angle between $\angle \mathrm{C} 1-\mathrm{O} 1-\mathrm{CH} 2$ was found $114.6^{\circ}$ for $\mathbf{3}, 114.4^{\circ}$ for $\mathbf{4}$, $114.5^{\circ}$ for $\mathbf{5}, 114.5^{\circ}$ for $\mathbf{6}$, and $114.9^{\circ}$ for $\mathbf{7 a}$ supported the above observation.

Knowing conformational structures of 4-7a,b, we were interested to know the effect acyl groups at other position and different chain lengths as in 89a-d (Figure 2).

It is evident from Table 2 that addition of acetyl group at C-3 position of rhamnopyranoside 3 formed 4- $\mathrm{O}$-acetate $\mathbf{8}$ and bond angles increased small amount at $\angle \mathrm{C} 2-\mathrm{C} 3-\mathrm{C} 4$ and $\angle \mathrm{C} 4-\mathrm{C} 5-\mathrm{O} 5$, and decreased very small in other positions.

Also, its dihedral angle increased little amount $\left(3^{\circ}\right)$ at $\angle \mathrm{H} 2-\mathrm{C} 2-\mathrm{C} 3-\mathrm{H} 3$ and remains almost same to compound 3 at other positions. Although both the 3-O-acetate 8 and 4-O-acetate 6 seem to exist in ${ }^{1} C_{4}$ chair conformation (Figure 4 and 5), their bond angles and dihedral angles differs slightly. This clearly indicated that the position of acyl group imposes a small effect on their pyranose chair conformation. 
Farzana Islam, Md. Rezaur Rahman, Mohammed M. Matin

Again, we checked effect of chain length (5C to $14 \mathrm{C}$ ) at C-2 and C-4 positions of 8 (as in 9a-d) on conformations. Addition of five-carbon (5C) acyl groups at C-2 and C-4 positions as in 9a didn't alter bond angles considerably as compared to $\mathbf{8}$. However, dihedral angles decreased at $\angle \mathrm{H} 1-\mathrm{C} 1-$ $\mathrm{C} 2-\mathrm{H} 2\left(14^{\circ}\right)$ and $\angle \mathrm{H} 3-\mathrm{C} 3-\mathrm{C} 4-\mathrm{H} 4\left(7^{\circ}\right)$, and increase at $\angle \mathrm{H} 2-\mathrm{C} 2-\mathrm{C} 3-\mathrm{H} 3\left(10^{\circ}\right)$ as compared to the compound $\mathbf{8}$.

As shown in Figure 5, its conformational structure remains in conformity with ${ }^{1} C_{4}$ chair conformation although bond and dihedral angle change must impose little change in conformation.

Elongation of chain length to $6 \mathrm{C}-14 \mathrm{C}$ at these C-2 and $\mathrm{C}-4$ positions indicated almost similar bond angles and dihedral angles. All these observations indicated that addition of more acyl groups might have little change on the conformation structure but chain elongation at the same position didn't affect conformation too much of rhamnopyranoside.

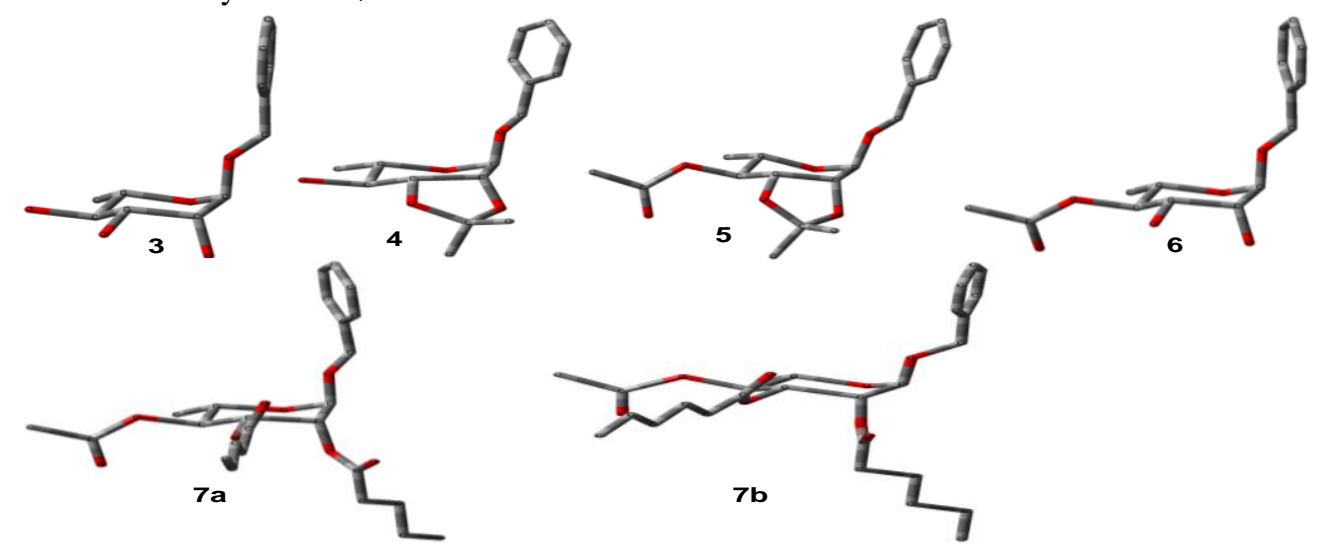

Figure 4. DFT optimized conformation of 3-6 and 7a,b (H atoms are not shown).

Table 2. Bond angle and dihedral angle of rhamnopyranoside 8-9a,d.

\begin{tabular}{|c|c|c|c|c|c|c|}
\hline \multirow{2}{*}{ Molecule } & \multicolumn{6}{|c|}{ Bond angle in degree } \\
\hline & $\mathrm{O} 5-\mathrm{C} 1-\mathrm{C} 2$ & $\mathrm{C} 1-\mathrm{C} 2-\mathrm{C} 3$ & $\mathrm{C} 2-\mathrm{C} 3-\mathrm{C} 4$ & $\mathrm{C} 3-\mathrm{C} 4-\mathrm{C} 5$ & $\mathrm{C} 4-\mathrm{C} 5-\mathrm{O} 5$ & $\mathrm{C} 5-\mathrm{O} 5-\mathrm{C} 1$ \\
\hline 3 & 113.7 & 111.3 & 110.8 & 110.4 & 107.3 & 115.3 \\
\hline 8 & 112.6 & 111.2 & 112.7 & 109.7 & 110.5 & 114.9 \\
\hline 9a & 111.4 & 109.7 & 110.7 & 110.4 & 109.0 & 115.0 \\
\hline $9 b$ & 111.4 & 109.8 & 110.8 & 110.5 & 108.9 & 115.0 \\
\hline $9 c$ & 111.4 & 109.8 & 110.8 & 110.3 & 109.0 & 114.9 \\
\hline \multirow[t]{3}{*}{ 9d } & 111.0 & 109.2 & 110.6 & 110.3 & 108.2 & 117.8 \\
\hline & \multicolumn{6}{|c|}{ Dihedral angle, in degree } \\
\hline & $\mathrm{H} 1-\mathrm{C} 1-\mathrm{C} 2-\mathrm{H} 2$ & \multicolumn{2}{|c|}{$\mathrm{H} 2-\mathrm{C} 2-\mathrm{C} 3-\mathrm{H} 3$} & H3-C3-C4-H4 & \multicolumn{2}{|c|}{$\mathrm{H} 4-\mathrm{C} 4-\mathrm{C} 5-\mathrm{H} 5$} \\
\hline 3 & 76.12 & \multicolumn{2}{|c|}{49.26} & -177.54 & \multicolumn{2}{|c|}{-177.44} \\
\hline 8 & 77.89 & \multicolumn{2}{|l|}{46.03} & -168.93 & \multicolumn{2}{|l|}{176.55} \\
\hline $9 \mathbf{a}$ & 65.68 & \multicolumn{2}{|l|}{56.19} & -175.40 & \multicolumn{2}{|l|}{175.78} \\
\hline $9 b$ & 65.91 & \multicolumn{2}{|l|}{55.80} & -175.02 & \multicolumn{2}{|l|}{175.74} \\
\hline $9 c$ & 65.82 & \multicolumn{2}{|l|}{55.98} & -175.12 & \multicolumn{2}{|l|}{175.82} \\
\hline 9d & 66.29 & \multicolumn{2}{|l|}{56.70} & -175.69 & \multicolumn{2}{|l|}{174.76} \\
\hline
\end{tabular}

*All these values were calculated from DFT (B3LYP) method and 6-31G basis sets. 

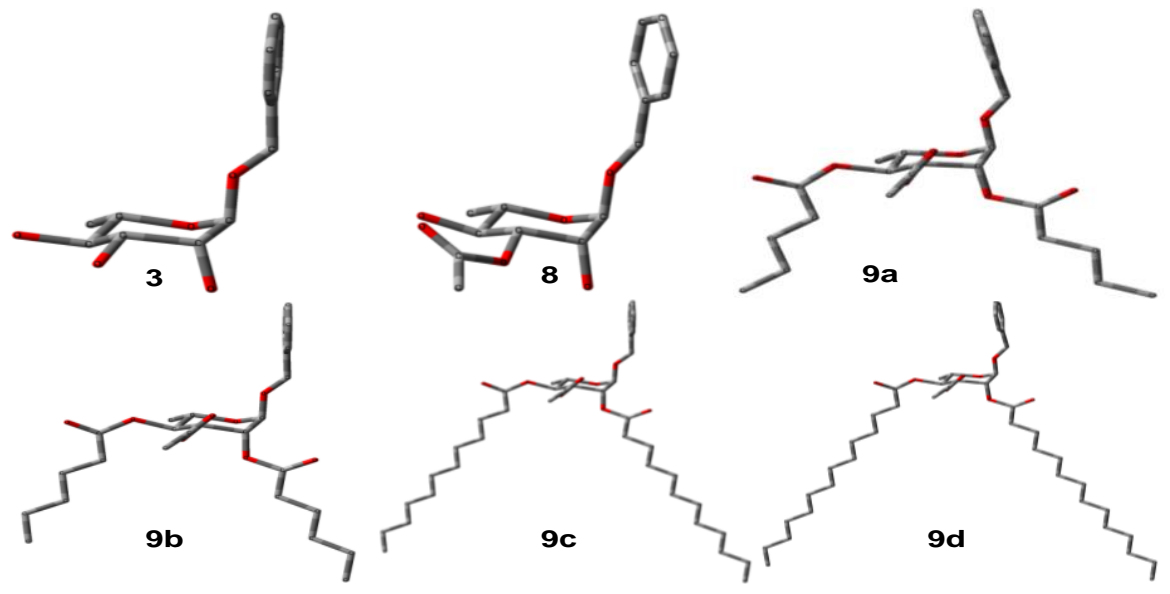

Figure 5. DFT optimized conformation of $\mathbf{8}$ and $\mathbf{9 a - d}$ (H atoms are not shown).

\subsection{Thermodynamic properties}

Some thermodynamic properties like electronic energy (EE), enthalpy, Gibb's free energy (GFE), entropy and dipole moment (DM) of all the rhamnopyranosides 3-9a-d are predicted from their DFT optimized structures (Table 3). With the increase of molecular size and atoms their EE increased as usual [53]. It was noticed that positional change of acetyl group as in 4- $O$-acetate $\mathbf{6}$ and 3-O-acetate $\mathbf{8}$ affect their entropy and dipole moment. The lower entropy and dipole moment of 8 (156.4 cal/mol-K and 3.64 Debye) than 6 (158.5 $\mathrm{cal} / \mathrm{mol}-\mathrm{K}$ and 4.28 Debye) clearly indicated more stability of 3-O-acetate 8 than $4-O$-acetate 6 . On the contrary, compound $\mathbf{8}$ should be less reactive than compound 6.
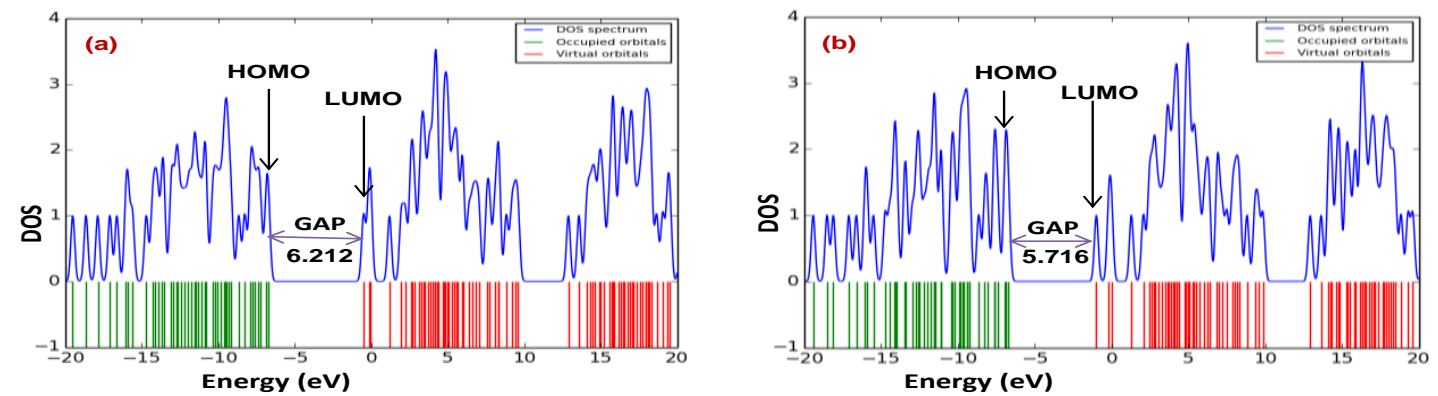

Figure 6. DOS plot of compound (a) 6 and (b) 8 .

Table 3. Some thermodynamic properties of 3-9a-d.

\begin{tabular}{ccccccc}
\hline Compound & $\mathbf{M F}$ & $\begin{array}{c}\mathbf{E E} \\
\text { (Hartree) }\end{array}$ & $\begin{array}{c}\text { Enthalpy } \\
\text { (Hartree) }\end{array}$ & $\begin{array}{c}\text { GFE } \\
\text { (Hartree) }\end{array}$ & $\begin{array}{c}\text { Entropy } \\
\text { (cal/mol-K) }\end{array}$ & $\begin{array}{c}\text { DM } \\
\text { (Debye) }\end{array}$ \\
\hline $\mathbf{3}$ & $\mathrm{C}_{13} \mathrm{H}_{18} \mathrm{O}_{5}$ & -882.0556 & -881.7352 & -881.7998 & 135.972 & 2.7199 \\
$\mathbf{4}$ & $\mathrm{C}_{16} \mathrm{H}_{22} \mathrm{O}_{5}$ & -998.7613 & -998.3750 & -998.4466 & 150.750 & 1.3104 \\
$\mathbf{5}$ & $\mathrm{C}_{18} \mathrm{H}_{24} \mathrm{O}_{6}$ & -1151.3750 & -1150.9471 & -1151.0282 & 170.713 & 2.5949 \\
$\mathbf{6}$ & $\mathrm{C}_{15} \mathrm{H}_{20} \mathrm{O}_{6}$ & -1034.6679 & -1034.3061 & -1034.3814 & 158.461 & 4.2776 \\
$\mathbf{7 a}$ & $\mathrm{C}_{25} \mathrm{H}_{36} \mathrm{O}_{8}$ & -1575.7204 & -1575.0949 & -1575.2084 & 238.959 & 2.0085 \\
$\mathbf{7 b}$ & $\mathrm{C}_{27} \mathrm{H}_{40} \mathrm{O}_{8}$ & -1654.3286 & -1653.6429 & -1653.7638 & 254.434 & 2.0449 \\
$\mathbf{8}$ & $\mathrm{C}_{15} \mathrm{H}_{20} \mathrm{O}_{6}$ & -1034.6689 & -1034.3072 & -1034.3815 & 156.418 & 3.6457 \\
$\mathbf{9 a}$ & $\mathrm{C}_{25} \mathrm{H}_{36} \mathrm{O}_{8}$ & -1575.7093 & -1575.0840 & -1575.1986 & 241.089 & 4.6646 \\
$\mathbf{9 b}$ & $\mathrm{C}_{27} \mathrm{H}_{40} \mathrm{O}_{8}$ & -1654.3174 & -1653.6320 & -1653.7530 & 254.501 & 4.6841 \\
$\mathbf{9 c}$ & $\mathrm{C}_{39} \mathrm{H}_{64} \mathrm{O}_{8}$ & -2125.9663 & -2124.9197 & -2125.0825 & 342.707 & 4.7308 \\
$\mathbf{9 d}$ & $\mathrm{C}_{43} \mathrm{H}_{72} \mathrm{O}_{8}$ & -2268.2713 & -2267.0324 & -2267.2043 & 361.783 & 5.5791 \\
\hline
\end{tabular}

* EE indicates RB3LYP energy 


\subsection{Molecular orbital properties of 3-9a-d}

The molecular orbital related HOMO (highest occupied molecular orbital), LUMO (lowest unoccupied molecular orbital) energy levels [54], HOMO-LUMO gap, hardness [55-57] and softness of rhamnopyranosides are mentioned in Table 4 (Figure 6). Here, $\eta=\mathrm{Gap} / 2$ and $S=1 / \eta$. For most of these rhamnopyranosides (except 9d) HOMO, LUMO and HOMO-LUMO gap was found almost similar. Hence, addition of acetonide group or acyl group(s) has not considerably changed their hardness and softness. However, 4-O-acetate 6 $(\sim 3.1)$ has greater hardness than the 3-O-acetate 8 ( 2.9). To our surprise compound 9d has lower HOMO-LUMO gap $(5.0 \mathrm{eV})$ and hence lower hardness and higher softness than the other rhamnopyranosides.

\subsection{MEP of synthesized rhamnopyranosides}

Molecular electrostatic potential (MEP) correlates with dipole moment, electronegativity, and partial charges. It is a very useful property for analyzing the relative polarity, and predicting molecular reactive behavior especially to forecast the reactive sites for electrophilic and nucleophilic attack. MEP can be determined experimentally as well as computationally. Here, MEP of all the molecules are predicted from their DFT optimized structures using WebMo server [39] and shown as three dimensional diagrams of molecules in Figure 7.

In the MEP red zone indicates the lowest and blue zone as the highest electrostatic potential energy value (Figure 7). Also, red color represents maximum negative area and favorable site for electrophilic attack, blue color represents the maximum positive area and favorable site for nucleophilic attack, and green color indicates zero potential area. It is clear from Figure 7 that with the addition of acetonide group, as in $\mathbf{4}$, decreases both electrophilicity (-0.1377) and nucleophilicity $(+0.1136)$ than non-acetonide $3 \quad(-0.1506$ to $+0.1645)$. While, in general, with the incorporation of acyl group(s) to the rhamnopyranoside skeleton (as in 6, 7a,b, 8, 9a-d) intensity of red color is increased and hence indicating the favorable site for electrophilic attack of these compounds. An important observation is that 4-O-acetate 6 has higher red value $(-0.212)$ than the $3-O$-acetate 8 (0.1760 ) which is in conformity with our previous observation on the basis of entropy and dipole moment (Table 3) that $\mathbf{6}$ is more reactive than $\mathbf{8}$. Overall, rhamnopyranoside esters are more favorable for electrophilic reaction than nucleophilic attack.

Table 4. Energy (eV) of HOMO, LUMO, energy gap, hardness, and softness of 3-9a-d.

\begin{tabular}{cccccc}
\hline Compound & $\boldsymbol{\varepsilon}$ номо & $\boldsymbol{\varepsilon}_{\text {LUMO }}$ & Gap & Hardness $(\boldsymbol{\eta})$ & Softness $(\boldsymbol{S})$ \\
\hline $\mathbf{3}$ & -6.608 & -0.0376 & 6.570 & 3.285 & 0.304 \\
$\mathbf{4}$ & -6.660 & -0.120 & 6.540 & 3.270 & 0.306 \\
$\mathbf{5}$ & -6.730 & -0.191 & 6.539 & 3.270 & 0.306 \\
$\mathbf{6}$ & -6.704 & -0.492 & 6.212 & 3.106 & 0.322 \\
$\mathbf{7 a}$ & -6.691 & -0.358 & 6.333 & 3.167 & 0.316 \\
$\mathbf{7 b}$ & -6.681 & -0.357 & 6.324 & 3.162 & 0.316 \\
$\mathbf{8}$ & -6.697 & -0.981 & 5.716 & 2.858 & 0.350 \\
$\mathbf{9 a}$ & -6.652 & -0.497 & 6.155 & 3.078 & 0.325 \\
$\mathbf{9 b}$ & -6.652 & -0.491 & 6.161 & 3.081 & 0.325 \\
$\mathbf{9 c}$ & -6.654 & -0.490 & 6.164 & 3.082 & 0.325 \\
$\mathbf{9 d}$ & -8.920 & -3.909 & 5.011 & 2.501 & 0.400 \\
\hline
\end{tabular}



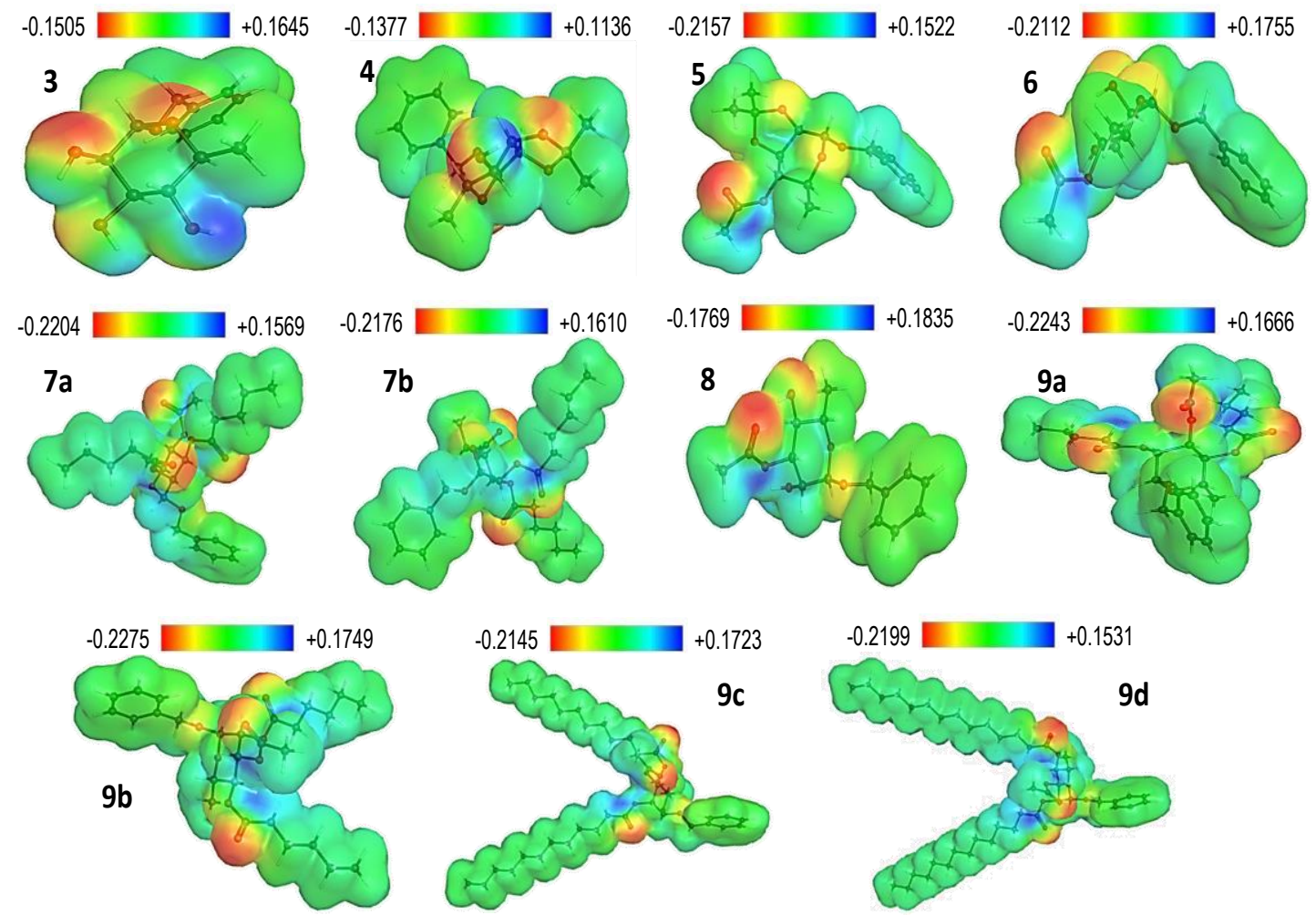

Figure 7. Molecular electrostatic potential map of 3- 9a-d.

\section{Conclusion}

As most of the SEs is syrupy in nature their structure can't be elucidated by X-ray crystallography. Hence, the current work presents the DFT optimized structures of two ester series of benzyl $\alpha$-L-rhamnopyranosides. Detailed conformational study of compound 3-9a-d importantly indicated that the fusion of a fivemembered acetonide ring with the six-membered pyranose ring of benzyl rhamnopyranoside molecule created huge distortion in its ${ }^{1} C_{4}$ chair conformation. The number, position and length of ester chain(s) as added to the rhamnopyranoside ring also caused a very minor distortion in ${ }^{1} C_{4}$ chair conformation with respect to bond angles and dihedral angles. Several thermodynamic, molecular orbital and molecular electrostatic potential properties are also discussed with respect to the structural modification of the synthetic benzyl $\alpha-\mathrm{L}-$ rhamnopyranosides.

\section{Acknowledgement}

The authors highly acknowledge the research support from the Research and Publication Cell, University of Chittagong, Bangladesh (2021, Special).

\section{References}

[1] R. Hevey, Strategies for the development of glycomimetic drug candidates. Pharmaceuticals 12(2) (2019) 55. https://doi.org/10.3390/ph12020055

[2] H.M. Ei-Laithy, O. Shoukry, L.G.Mahran, Novel sugar esters proniosomes for transdermal delivery of vinpocetine: Preclinical and clinical studies. European Journal of Pharmaceutics and Biopharmaceutics $77 \quad$ (2011) 43-55. https://doi.org/10.1016/j.ejpb.2010.10.011

[3] D.D. Dhavale, M.M. Matin, Selective sulfonylation of 4-C-hyroxymethyl- $\beta-\mathrm{L}$ threo-pento-1,4-furanose: Synthesis of bicyclic diazasugars. Tetrahedron 60(19) (2004) 4275-4281. https://doi.org/10.1016/j.tet.2004.03.034

[4] D.D. Dhavale, M.M. Matin, T. Sharma, S.G. Sabharwal, Synthesis and evaluation of glycosidase inhibitory activity of octahydro2H-pyrido[1,2-a]pyrimidine and octahydroimidazo[1,2-a]pyridine bicyclic diazasugars. Bioorganic \& Medicinal Chemistry 12 (2004) 4039-4044. https://doi.org/10.1016/j.bmc.2004.05.030

[5] A.M. Gumel, M.S.M. Annuar, T. Heidelberg, Y. Chisti, Lipase mediated synthesis of sugar fatty acid esters. Process Biochemistry 46 
(2011)

2079-90.

https://doi.org/10.1016/j.procbio.2011.07.021

[6] M.M. Matin, P. Chakraborty, M.S. Alam, M.M. Islam, U. Hanee, Novel mannopyranoside esters as sterol $14 \alpha$ demethylase inhibitors: Synthesis, PASS predication, molecular docking, and pharmacokinetic studies. Carbohydrate Research $496 \quad$ (2020) 108130. https://doi.org/10.1016/j.carres.2020.108130

[7] Y.L. Teng, S.G. Stewart, Y.W. Hai, X. Li, M.G. Banwell, P. Lan, Sucrose fatty acid esters: Synthesis, emulsifying capacities, biological activities and structure-property profiles. Critical Reviews in Food Science and Nutrition 2020. https://doi.org/10.1080/10408398.2020.1798 346

[8] M.M. Matin, S.C. Bhattacharjee, P. Chakraborty, M.S. Alam, Synthesis, PASS predication, in vitro antimicrobial evaluation and pharmacokinetic study of novel n-octyl glucopyranoside esters. Carbohydrate Research $485 \quad$ (2019) 107812. https://doi.org/10.1016/j.carres.2019.107812

[9] M.M. Matin, M.M.H. Bhuiyan, A.K.M.S. Azad, M.H.O. Rashid, Synthesis of 6-Ostearoyl-1,2-O-isopropylidene- $\alpha$-D-glucofuranose derivatives for antimicrobial evaluation. Journal of Physical Science 26(1) (2015) 1-12.

[10] D.R. Perinelli, S. Lucarini, L. Fagioli, R. Campana, D. Vllasaliu, A. Duranti, L. Casettari, Lactose oleate as new biocompatible surfactant for pharmaceutical applications. European Journal of Pharmaceutics and Biopharmaceutics 124 (2018) $55-62$. https://doi.org/10.1016/j.ejpb.2017.12.008

[11] A.V. Demchenko, Stereoselective chemical 1,2-cis O-glycosylation: From 'Sugar Ray' to modern techniques of the 21 st century. Synlett (2003) 1225-1240. https://doi.org/10.1055/s2003-40349

[12] D. Crich, Chemistry of glycosyl triflates:Synthesis of $\beta$-mannopyranosides. Journal of Carbohydrate Chemistry 21 (2002) 663-686. https://doi.org/10.1081/CAR120016486

[13] M.M. Matin, M.M.H. Bhuiyan, E. Kabir, A.F.M. Sanaullah, M.A. Rahman, M.E. Hossain, M. Uzzaman, Synthesis, characterization, ADMET, PASS predication, and antimicrobial study of 6-O-lauroyl mannopyranosides. Journal of Molecular

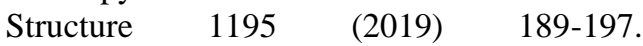
https://doi.org/10.1016/j.molstruc.2019.05.10 2
[14] B. Ren, L. Zhang, M. Zhang, Progress on selective acylation of carbohydrate hydroxyl groups. Asian Journal Organic Chemistry 8 (2019) 1813-1823. https://doi.org/10.1002/ajoc.201900400

[15] M.M. Matin, T. Sharma, S.G. Sabharwal, D.D. Dhavale, Synthesis and evaluation of glycosidase inhibitory activity of 5-hydroxy substituted isofagomine analogues. Organic \& Biomolecular Chemistry 3 (2005) 1702-1707. https://doi.org/10.1039/b418283a

[16] M.M. Matin, P. Chakraborty, Synthesis, spectral and DFT characterization, PASS predication, antimicrobial, and ADMET studies of some novel mannopyranoside esters. Journal of Applied Science \& Process Engineering $\quad 7(2) \quad$ (2020) 572-586. https://doi.org/10.33736/jaspe.2603.2020

[17] A.R. Buzatu, A.E. Frissen, L.A.M. van den Broek, A. Todea, M. Motoc, C.G. Boeriu, Chemoenzymatic synthesis of new aromatic esters of mono- and oligosaccharides. $\begin{array}{llll}\text { Processes } & 8 & (2020) & 1638 .\end{array}$ https://doi.org/10.3390/pr8121638

[18] M.M. Matin, M.S. Hasan, M. Uzzaman, M.M.H. Bhuiyan, S.M. Kibria, M.E. Hossain, M.H.O. Roshid, Synthesis, spectroscopic characterization, molecular docking, and ADMET studies of mannopyranoside esters as antimicrobial agents. Journal of Molecular $\begin{array}{lll}\text { Structure } & 1222 \quad \text { (2020) } & 128821 .\end{array}$ https://doi.org/10.1016/j.molstruc.2020.1288 21

[19] A. Richel, P. Laurent, B. Wathelet, J.-P. Wathelet, M. Paquot, Microwave-assisted conversion of carbohydrates. State of the art and outlook. Comptes Rendus Chimie 14 (2011) 224-234. https://doi.org/10.1016/j.crci.2010.04.004

[20] S.R. Kim, Y.C. Kim, Neuroprotective phenylpropanoid esters of rhamnose isolated from roots of Scrophularia buergeriana. Phytochemistry 54 2000, 503-509. https://doi.org/10.1016/s00319422(00)00110-2

[21] X.Z. Dong, C.L. Huang, B.Y. Yu, Y. Hu, L.H. $\mathrm{Mu}, \mathrm{P}$. Liu, Effect of Tenuifoliside A isolated from Polygala tenuifolia on the ERK and PI3K pathways in C6 glioma cells. Phytomedicine $21 \quad$ (2014) 1178-1188. https://doi.org/10.1016/j.phymed.2014.04.02 2

[22] Y. Tian, W. Liu, Y. Lu, Y. Wang, X. Chen, S. Bai, Y. Zhao, T. He, F. Lao, Y. Shang, Y. Guo, G. She, Naturally occurring cinnamic acid sugar ester derivatives. Molecules 21 (2016) 1402. https://doi.org/10.3390/molecules21101402 
[23] M. Mihoub, A. Pichette, B. Sylla, C. Gauthier, J. Legault, Bidesmosidic betulin saponin bearing L-rhamnopyranoside moieties induces apoptosis and inhibition of lung cancer cells growth in vitro and in vivo. PLoS ONE 13(3) (2018) 0193386. https://doi.org/10.1371/journal.pone.0193386

[24] A.K.M.S. Kabir, M.M. Matin, A. Hossain, M.A. Sattar, Synthesis and antimicrobial activities of some rhamnopyranoside derivatives. Journal of Bangladesh Chemical Society 16(2) (2003) 85-93.

[25] M.M. Matin, M. Ibrahim, Synthesis of some methyl 4-O-octanoyl- $\alpha$-L-rhamnopyranoside derivatives. Journal of Applied Sciences Research 6(10) (2010) 1527-1532.

[26] M.M. Matin, M. Ibrahim, M.S. Rahman, Antimicrobial evaluation of methyl 4-Oacetyl- $\alpha$-L-rhamnopyranoside derivatives. The Chittagong University Journal of Biological Sciences 3(1\&2) (2008) 33-43. http://dx.doi.org/10.3329/cujbs.v3i1.13404

[27] M.M. Matin, M.H.O. Roshid, S.C. Bhattacharjee, A.K.M.S. Azad, PASS predication, antiviral, in vitro antimicrobial, and ADMET studies of rhamnopyranoside esters. Medical Research Archives 8(7) (2020) https://doi.org/10.18103/mra.v8i7.2165

[28] J. Qian, D. Hunkler, H. Rimpler, Iridoidrelated aglycone and its glycosides from Scrophularia ningpoensis. Phytochemistry 31 (1992) 905-911. https://doi.org/10.1016/0031-9422(92)80037$\mathrm{F}$

[29] J.A. Duck, E.S. Ayensu, 1985, Medical Plants of China. Algonac, MI, p. 599.

[30] F.O. Akong, S. Bouquillon, Efficient syntheses of bolaform surfactants from 1rhamnose and/or 3-(4hydroxyphenyl)propionic acid. Green $\begin{array}{llll}\text { Chemistry } & 17 & \text { (2015) 3290-3300. }\end{array}$ https://doi.org/10.1039/C5GC00448A

[31] X.-D. Yang, Z.-Y. Li, S.-X. Mei, J.-F. Zhao, H.-B. Zhang, L. Li, Two new phenylpropanoid esters of rhamnose from Lagotis yunnanensis. Journal of Asian Natural Products Research 5(3) (2003) 223-226. https://doi.org/10.1080/10286020310000933 66

[32] G.M. Lipkind, A.S. Shashkov, O.A. Nechaev, V.I. Torgov, V.N. Shibaev, N.K. Kochetkov, Conformations of branched trisaccharides with vicinal substitution according to the nuclear Overhauser effect and theoretical calculations. III. The spectra of 13C-NMR and trisaccharides conformation with galactose residue in a node branching. Bioorg. Khim. 15 (1989) 1366-1374.

[33] G.M. Lipkind, N.E. Nifantev, A.S. Shashkov, N.K. Kochetkov, NMR and conformational study of branched oligosaccharides containing 2,3-disubstituted residues of $\alpha$-L-rhamnose. Canadian Journal of Chemistry 68 (1990) 1238-1250. https://doi.org/10.1139/v90-192

[34] R. Pendrill, L. Eriksson, G. Widmalma, Methyl 4-O-benzyl- $\alpha$-L-rhamnopyranoside. Acta Crystallographica Section E 70 (2014) o561-0562.

https://doi.org/10.1107/S1600536814007922

[35] R.A. Mendes, S.K.C. Almeida, I.N. Soares, C.A. Barboza, R.G. Freitas, A. Brown, G.L.C. de Souza, A computational investigation on the antioxidant potential of myricetin 3,4-diO- $\alpha$-L-rhamnopyranoside. Journal of Molecular Modeling 24 (2018) 133. https://doi.org/10.1007/s00894-018-3663-2

[36] M.M. Matin, M.M.H. Bhuiyan, A.K.M.S. Azad, N. Akther, Design and synthesis of benzyl 4-O-lauroyl- $\alpha$-L-rhamnopyranoside derivatives as antimicrobial agents. Current Chemistry Letters 6(1) (2017) 31-40. https://doi.org/10.5267/j.ccl.2016.10.001

[37] M.M. Matin, A.R. Nath, O. Saad, M.M.H. Bhuiyan, F.A. Kadir, S.B. Abd Hamid, A.A. Alhadi, M.E. Ali, W.A. Yehye, Synthesis, PASS-predication and in vitro antimicrobial activity of benzyl 4-O-benzoyl- $\alpha$-Lrhamnopyranoside derivatives. International Journal of Molecular Sciences 17(9) (2016) 1412. https://doi.org/10.3390/ijms 17091412

[38] M.M. Matin, Synthesis and antimicrobial study of some methyl 4-O-palmitoyl- $\alpha$-Lrhamnopyranoside derivatives. Orbital: The Electronic Journal of Chemistry 6(1) (2014) 20-28.

https://doi.org/10.17807/orbital.v6i1.553

[39] M.M. Matin, M.Z. Iqbal, Methyl 4-O-(2chlorobenzoyl)- $\alpha$-L-rhamnopyranosides:

Synthesis, characterization, and thermodynamic studies. Orbital: The Electronic Journal of Chemistry 13(1) (2021) 19-27.

http://dx.doi.org/10.17807/orbital.v13i1.1532

[40] M.M. Matin, N. Islam, A. Siddika, S.C. Bhattacharjee, Regioselective synthesis of some rhamnopyranoside esters for PASS predication, and ADMET studies. Journal of the Turkish Chemical Society Section A: Chemistry 8(1) (2021) 363-374. https://doi.org/10.18596/jotcsa.829658

[41] MM Matin, M Uzzaman, SA Chowdhury, MMH Bhuiyan, In vitro antimicrobial, physicochemical, pharmacokinetics, and molecular docking studies of benzoyl uridine 
esters against SARS-CoV-2 main protease. Journal of Biomolecular Structure and Dynamics (2020). https://doi.org/10.1080/07391102.2020.1850 358.

[42] A.K.M.S. Kabir, M.M. Matin, Regioselective monoacylation of a derivative of L-rhamnose. Journal of Bangladesh Academy of Sciences 21(1) (1997) 83-88.

[43] M.J. Frisch, G.W. Trucks, H.B. Schlegel, G.E. Scuseria, M.A. Robb, J.R. Cheeseman, G. Scalmani, V. Barone, B. Mennucci, G.A. Petersson, H. Nakatsuji, M. Caricato, X. Li, H.P. Hratchian, A.F. Izmaylov, J. Bloino, G. Zheng, J.L. Sonnenberg, M. Hada, M. Ehara, K. Toyota, R. Fukuda, J. Hasegawa, M. Ishida, T. Nakajima, Y. Honda, O. Kitao, H. Nakai, T. Vreven, J.A. Montgomery, Jr., J. E. Peralta, F. Ogliaro, M. Bearpark, J.J. Heyd, E. Brothers, K.N. Kudin, V.N. Staroverov, T. Keith, R. Kobayashi, J. Normand, K. Raghavachari, A. Rendell, J. C. Burant, S.S. Iyengar, J. Tomasi, M. Cossi, N. Rega, J.M. Millam, M. Klene, J.E. Knox, J.B. Cross, V. Bakken, C. Adamo, J. Jaramillo, R. Gomperts, R.E. Stratmann, O. Yazyev, A.J. Austin, R. Cammi, C. Pomelli, J.W. Ochterski, R. L. Martin, K. Morokuma, V.G. Zakrzewski, G.A. Voth, P. Salvador, J.J. Dannenberg, S. Dapprich, A.D. Daniels, O. Farkas, J. B. Foresman, J.V. Ortiz, J. Cioslowski, and D.J. Fox, Gaussian 09W, Revision D.01, Gaussian, Inc, Wallingford CT, 2013.

[44] A. D. Becke, Density-functional thermochemistry. III. The role of exact exchange. The Journal of Chemical Physics $98 \quad$ (1993) 5648-5652. https://doi.org/10.1063/1.464913

[45] C. Lee, W. Yang, R. G. Parr, Development of the Colle-Salvetti correlation-energy formula into a functional of the electron density. Physics Review B37 (1988) 785-789. https://doi.org/10.1103/PhysRevB.37.785

[46] R. Ditchfield, W. J. Hehre, and J. A. Pople, Self-Consistent Molecular Orbital Methods. 9. Extended Gaussian-type basis for molecular-orbital studies of organic molecules. The Journal of Chemical Physics $54 \quad$ (1971) 724. http://dx.doi.org/10.1063/1.1674902

[47] W.J. Hehre, R. Ditchfield, J.A. Pople, SelfConsistent Molecular Orbital Methods. 12. Further extensions of Gaussian-type basis sets for use in molecular-orbital studies of organicmolecules. The Journal of Chemical Physics $56 \quad$ 2257-2261. http://dx.doi.org/10.1063/1.1677527
[48] T. Sawada, T. Hashimoto, H. Nakano, M. Shigematsu, H. Ishida, M. Kiso, Conformational study of $\alpha-\mathrm{N}$-acetyl-Dneuraminic acid by density functional theory. Journal of Carbohydrate Chemistry 25(5) (2006) 387-405. http://dx.doi.org/10.1080/0732830060077880 1

[49] M.A. Shalaby, F.R. Fronczek, E.S. Younathan, Structural analysis of methyl $\alpha-\mathrm{L}-$ rhamnopyranoside in the solid state. Carbohydrate Research 258 (1994) 267-274. https://doi.org/10.1016/0008-6215(94)84092$\mathrm{X}$

[50] M.A. Shalaby, F.R. Fronczek, E.S. Younathan, Conformational features of rhamnopyranose derivatives: The molecular structure of methyl 2,3,4-tri-O-acetyl- $\alpha$-Lrhamnopyranoside. Carbohydrate Research 264(2) (1994) 173-180. https://doi.org/10.1016/S00086215(05)80003-5

[51] I. Noorbatcha, S. Hassan, A. Hamid, A. Hadi, K. Awang, Ab-initio geometry-optimization and NMR studies of chemical constituents of Piper sarmentosum. Malaysian Journal of Science 21 (2002) 143-147.

[52] A. Kumer, M.N. sarker, S. Paul, The Thermophysical, HOMO, LUMO, vibrational spectroscopy and QSAR study of morpholinium formate and acetate ionic liquid salts using computational method. Turkish Computational and Theoretical Chemistry 3(2) (2019) 59-68.

[53] M. Ali, M.H. Karim, M.M. Matin, Efficient synthetic technique, PASS predication, and ADMET studies of acylated n-octyl glucopyranosides. Journal of Applied Science \& Process Engineering 8(1) (2021) 648-659. https://doi.org/10.33736/jaspe.2823.2021

[54] R.G. Pearson, Absolute electronegativity and hardness correlated with molecular orbital theory. Proc. Natl. Acad. Sci. USA., 83 (1986) 8440-8441. https://doi.org/10.1073/pnas.83.22.8440

[55] T. Koopmans, Über die Zuordnung von Wellenfunktionen und Eigenwerten zu den Einzelnen Elektronen Eines Atoms. Physica 1 (1934) 104-113. https://doi.org/10.1016/S00318914(34)90011-2

[56] R.G. Parr, L.V. Szentpaly, S. Liu, Electrophilicity index. Journal of the American Chemical Society 121 (1999) 19221924. https://doi.org/10.1021/ja983494x

[57] R.G. Parr, R.G. Pearson, Absolute hardness: companion parameter to absolute electronegativity. Journal of the American 
Turkish Comp Theo Chem (TC\&TC), 5(1), (2021), 39-50

Farzana Islam, Md. Rezaur Rahman, Mohammed M. Matin

Chemical Society 105 (1983) 7512-7516.

https://doi.org/10.1021/ja00364a005 